\title{
Gaps in anterograde conduction in patients with the short PR interval, normal QRS complex syndrome
}

\author{
A. J. CAMM, D. E. WARD, AND R. A. J. SPURRELL \\ From the Department of Cardiology, St Bartholomew's Hospital, London
}

SUMMARY Of 8 patients with the short PR interval, normal QRS complex syndrome studied recently, 3 reported here displayed gaps in anterograde conduction. Atrial premature beats at decreasing coupling intervals conducted with minimal $\mathrm{AH}$ prolongation until a zone within the cardiac cycle was reached where conduction failed at a supra-Hisian level. Conduction resumed at earlier atrial coupling intervals and was associated with a sudden increase in the $\mathrm{AH}$ interval and the appearance of atrial echo beats with earliest atrial activation on the proximal coronary sinus electrogram.

It is suggested that the failure of anterograde conduction at relatively late atrial coupling intervals was caused by a short AH functional refractoriness produced by the pre-excitation of the lower AV junction by a partial AV nodal bypass. Conduction resumed only when early atrial premature beats found the extranodal pathway refractory and were transmitted with decremental delay through the AV node.

Inhomogeneity of refractoriness along the length of the atrioventricular (AV) transmission system may lead to gaps in anterograde conduction (Moe et al., 1965) where an atrial premature beat within a limited zone of the cardiac cycle fails to conduct anterogradely but both earlier and later atrial systoles conduct normally (Wit et al., 1970a). An early hypothesis (Durrer, 1968) suggested that such 'gap phenomena' might be explained by functional longitudinal duality of conduction at a site proximal to the location of conduction block during the gap. Many examples of gap phenomena have been described (Damato et al., 1976), but their explanation has not required the hypothesis of proximal dual conduction.

The syndrome of short PR interval, normal QRS complex associated with paroxysms of tachycardia (Clerc et al., 1938; Lown et al., 1952) provides an example of dual conduction pathways at AV nodal level (Denes et al., 1974b) which is often associated with gaps in anterograde conduction (Seipel et al., 1976). In this study the interplay between dual proximal conduction and distal conduction failure in 3 patients with the short PR interval, normal QRS complex syndrome is defined.

Received for publication 22 September 1977

\section{Patients and methods}

During the months of March to July 1977, 8 patients with the short PR interval, normal QRS complex syndrome were admitted for electrophysiological study. Of the 8 patients, 3 had anterograde conduction gaps and their clinical details are listed in Table 1. All 3 patients had PR intervals $\leqslant 0.12 \mathrm{~s}$ and QRS complexes $<0.10 \mathrm{~s}$. Two patients presented with repeated paroxysms of supraventricular tachycardia and the third patient suffered frequent attacks of atrial fibrillation with a rapid (180 to 240 beats per minute) ventricular response. There was no evidence of any underlying cardiac pathology or intercurrent disease in any of these patients.

Electrophysiological studies were performed in the non-sedated, post-absorptive state in the supine

Table 1 Clinical and electrocardiographic data

\begin{tabular}{lcccccc}
\hline Case & Age & Sex & $P R$ & $\begin{array}{c}Q R S \\
\text { duration }\end{array}$ & $\begin{array}{c}\text { QRS } \\
\text { frontal } \\
\text { axis }\end{array}$ & Presentation \\
\hline 1 & 50 & M & $0.12 \mathrm{~s}$ & $0.09 \mathrm{~s}$ & $+60^{\circ}$ & Paroxysmal SVT \\
2 & 20 & $\mathrm{M}$ & $0.11 \mathrm{~s}$ & $0.07 \mathrm{~s}$ & $+75^{\circ}$ & Paroxysmal SVT \\
3 & 33 & $\mathrm{M}$ & $0.12 \mathrm{~s}$ & $0.09 \mathrm{~s}$ & $+40^{\circ}$ & Paroxysmal AF \\
\hline \multicolumn{6}{l}{ SVT, supraventricular tachycardia; AF, atrial fibrillation. }
\end{tabular}


position. All medications had been withdrawn at least 4 days before the study. Bipolar electrode catheters with $1 \mathrm{~cm}$ interelectrode distance were introduced percutaneously via the right femoral vein and positioned in the high right atrium, against the septal leaflet of the tricuspid valve and in the apex of the right ventricle. A quadripolar electrode catheter with $1 \mathrm{~cm}$ electrode separations was passed via a left brachial vein into the coronary sinus. Recordings were made from the distal and proximal bipoles. All signals were filtered between 50 and $700 \mathrm{~Hz}$ and recorded simultaneously with three surface leads: I, aVF, and V1, on an Elema Mingograf recorder. Time markings at 1 second intervals were superimposed on an oscillating $50 \mathrm{~Hz}$ baseline. Stimulation was performed with a Devices $\mathbf{4 2 7 0}$ stimulator which delivered square wave pulses of $1.5 \mathrm{~ms}$ duration at an amplitude approximately twice the diastolic threshold. Signals were recorded during sinus rhythm and during incremental atrial pacing at rates between 100 and 160 beats per minute. Anterograde conduction characteristics were assessed by the atrial extrastimulus method in which a programmed atrial premature beat was introduced after a sequence of 8 regularly paced atrial systoles. Anterograde conduction studies were performed at several different basic pacing rates and after the intravenous infusion of $0.1 \mathrm{mg}$ per $\mathrm{kg}$ body weight of verapamil.

\section{DEFINITIONS}

The following abbreviations, terms, and definitions are used throughout the text:

$A_{1}, H_{1}, V_{1}$ : The atrial, His bundle, and ventricular electrogram during basic atrial pacing.

$A_{2}, H_{2}, V_{2}$ : The atrial, His bundle, and ventricular electrograms produced by premature atrial stimulation.

$P A$ : The interval between the earliest atrial activation and the intrinsic deflection of the atrial electrogram on the His bundle electrode.

$A H$ : The interval between the intrinsic deflection of the atrial electrogram and the intrinsic deflection of the His bundle electrogram on the His bundle electrode.

$H V$ : The interval between the intrinsic deflection of the His bundle electrogram and the earliest ventricular activation on any lead.

Anterograde conduction curve (Moe et al., 1956): A graphic representation of the results of the atrial extra-stimulus technique where $\mathrm{H}_{1} \mathrm{H}_{2}$ and $\mathrm{V}_{1} \mathrm{~V}_{2}$ intervals are plotted against their corresponding $\mathbf{A}_{1} \mathbf{A}_{2}$ values.

Fast (atrionodal) pathway ERP: Effective refractory period of the fast extranodal conduction pathway defined, in this report, as the shortest $\mathrm{A}_{1} \mathrm{~A}_{2}$ value before the occurrence of slow pathway conduction. This interval is the lower limit of the anterograde gap in conduction during which it is assumed that concealed fast pathway conduction continues.

Fast (atrionodal) pathway FRP : Functional refractory period of the fast extranodal pathway defined as being equal to the effective refractory period of this pathway. Extranodal fibres of the type described by James (1963) or Brechenmacher (1976) are composed of atrial myocardium or Purkinje-like tissue which ordinarily does not possess decremental conduction characteristics at longer coupling intervals of $\mathrm{A}_{1} \mathrm{~A}_{2}$. A definition which involved $\mathrm{H}_{1} \mathrm{H}_{2}$ measurements would include final common pathway conduction between the site of insertion of the extranodal pathway and the point from which the His bundle deflections were recorded.

Slow $(A H)$ pathway ERP: Effective refractory period of the slow $\mathrm{AH}$ conduction pathway defined as the longest $A_{1} A_{2}$ interval (not including $A_{1} A_{2}$ intervals during the anterograde gap) which is not conducted to the His bundle.

Slow $(A H)$ pathway FRP: Functional refractory period of the slow AH conduction pathway defined as the shortest $\mathrm{H}_{1} \mathrm{H}_{2}$ interval achieved by any $\mathrm{A}_{1} \mathrm{~A}_{2}$ value shorter than the ERP of the fast pathway.

Anterograde gap: A range of $\mathrm{A}_{1} \mathrm{~A}_{2}$ values within the cardiac cycle where $A_{2}$ does not result in a ventricular response bracketed by zones of intact conduction.

Atrial echo zone: A range of $\mathrm{A}_{1} \mathrm{~A}_{2}$ intervals in which $A_{2}$ results in a second atrial response (Ae) in which the earliest atrial activation occurs on the proximal coronary sinus electrogram.

\section{Results}

Conduction intervals during sinus rhythm are listed in Table 2. All 3 patients had short $\mathrm{AH}$ times $(\leqslant 60 \mathrm{~ms})$ but normal intra-atrial $(\mathrm{PA}=20-50 \mathrm{~ms})$ and specialised intraventricular $(\mathrm{HV}=35-50 \mathrm{~ms})$ conduction times. Incremental atrial pacing (Table 2) resulted in little or no AH prolongation.

Anterograde conduction characteristics (Fig. 1) as assessed by the atrial extrastimulus technique were abnormal in 3 respects: (1) atrial premature stimuli at progressively shorter coupling intervals resulted in minimal prolongation of the $\mathrm{A}_{2} \mathrm{H}_{2}$ time, until (2) total anterograde block developed, in all but one instance above the site from which the His bundle deflection was recorded, and (3) conduction resumed at shorter intervals of $A_{1} A_{2}$ with a sudden increase of the $\mathrm{A}_{2} \mathrm{H}_{2}$ interval and the simultaneous appearance of atrial echo beats or sustained tachycardia.

Recordings from case 2 are illustrated in Fig. 2. 
Table 2 Conduction intervals during sinus rhythm and incremental atrial pacing

\begin{tabular}{|c|c|c|c|c|c|}
\hline \multirow[t]{2}{*}{ Case } & \multicolumn{3}{|c|}{ Sinus rhythm } & \multicolumn{2}{|c|}{ Atrial pacing } \\
\hline & $P A$ & $A H$ & $H V$ & $\begin{array}{l}100 \mathrm{bpm} \\
A H\end{array}$ & $\begin{array}{l}160 \mathrm{bpm} \\
A H\end{array}$ \\
\hline $\begin{array}{l}1 \\
2 \\
3\end{array}$ & $\begin{array}{l}30 \\
25 \\
20\end{array}$ & $\begin{array}{l}55 \\
45 \\
60\end{array}$ & $\begin{array}{l}35 \\
40 \\
40\end{array}$ & $\begin{array}{l}55 \\
45 \\
60\end{array}$ & $\begin{array}{l}60 \\
45 \\
70\end{array}$ \\
\hline
\end{tabular}

Basic atrial pacing at a cycle length of $545 \mathrm{~ms}$ resulted in an $\mathrm{A}_{1} \mathrm{H}_{1}$ interval of $45 \mathrm{~ms}$ and an $\mathrm{H}_{1} \mathrm{~V}_{1}$ interval of $40 \mathrm{~ms}$. The QRS morphology throughout the study was that of right bundle-branch block. $\mathrm{A}_{1} \mathrm{~A}_{2}$ intervals above $350 \mathrm{~ms}$ did not produce $\mathrm{A}_{2} \mathrm{H}_{2}$ prolongation, but as the $A_{1} A_{2}$ interval was reduced to $310 \mathrm{~ms}$ the $\mathrm{A}_{2} \mathrm{H}_{2}$ interval increased to $80 \mathrm{~ms}$ and anterograde block occurred below the level of the His bundle. At an extrastimulus coupling interval of $300 \mathrm{~ms}$ block occurred at a supra-Hisian level. Conduction resumed at an $A_{1} A_{2}$ interval of $260 \mathrm{~ms}$ with an $\mathrm{A}_{2} \mathrm{H}_{2}$ interval of $185 \mathrm{~ms}$ and an atrial echo beat with earliest atrial activation on the proximal coronary sinus electrogram. Further reduction in the $A_{1} A_{2}$ interval resulted in conduction to the ventricles with appropriate $\mathrm{A}_{2} \mathrm{H}_{2}$ prolongation and atrial echo beats with a constant $\mathrm{H}_{2} \mathrm{Ae}$ time of $40 \mathrm{~ms}$ until anterograde block again occurred at an $\mathbf{A}_{1} \mathbf{A}_{2}$ interval of $220 \mathrm{~ms}$.

Similar results were obtained in cases 1 and 3 with the exception that anterograde block always occurred proximal to the His bundle (Fig. 1).

Reduction in the cycle length of the basic atrial pacing sequence resulted in all patients in attenuation or abolition of the anterograde gap in conduction (Table 3 ) because of improved final common pathway conduction or failure of slow pathway conduction.
After intravenous verapamil, slow pathway conduction at $A_{1} A_{2}$ intervals less than the refractory period of the fast pathway was abolished (Fig. 3). Fast pathway conduction was not affected by verapamil.

\section{Discussion}

In 1952 Lown et al. reported the association between a short PR interval on the resting 12-lead electrocardiogram and paroxysms of rapid heart action. This syndrome differs from the Wolff-ParkinsonWhite syndrome (1930) which is also characterised by a short PR interval, in that the QRS complex is narrow. It is now firmly established that at least the majority of examples of the Wolff-Parkinson-White syndrome result from an anomalous tract of tissue which bridges the annulus fibrosus and allows preexcitation of the ventricular myocardium by this abnormal route (Durrer et al., 1970). The attenuation of the PR interval in the Lown-Ganong-Levine syndrome is the result of a short $\mathrm{AH}$ interval (Castellanos et al., 1971; Mandel et al., 1971; Neuss et al., 1975) and occasionally additional shortening of the HV interval (Mandel et al., 1971; Both et al., 1975). By analogy with the Wolff-Parkinson-White syndrome the syndrome of short PR interval and normal QRS complex might be explained by preexcitation of the distal AV junction by a partial or complete AV nodal bypass tract as described by James (1963) or Brechenmacher (1976) (Castellanos et al., 1971; James and Scherf, 1971; Mandel et al., 1971). Such a tract of tissue has been histologically verified in one patient with the short PR interval, normal QRS complex syndrome (Brechenmacher et al., 1974). Nevertheless, the alternative explanation of a rapidly conducting intranodal pathway (Caracta

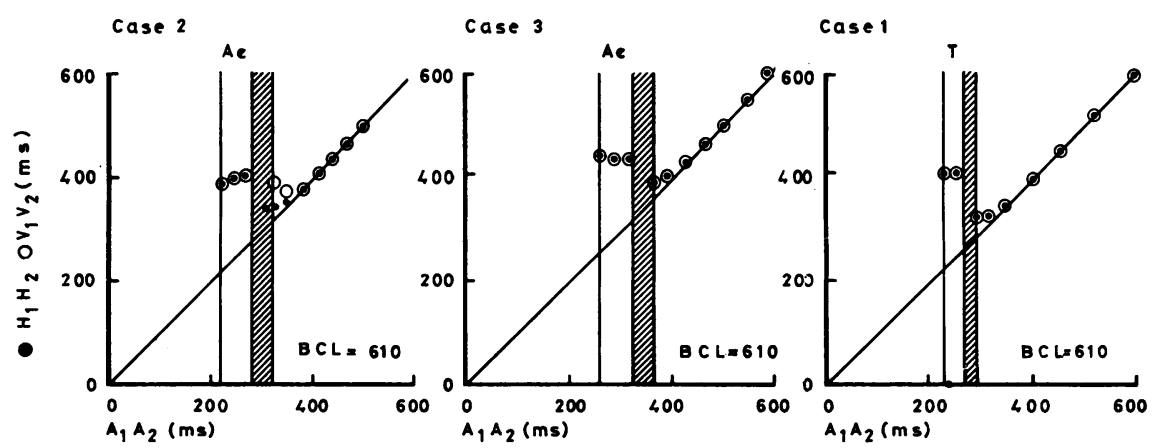

Fig. 1 Anterograde conduction curves in case 1, 2, and 3. The hatched area is the gap zone. Atrial echo zones $(A e)$ or tachycardia stimulation zone $(T)$ are indicated. 


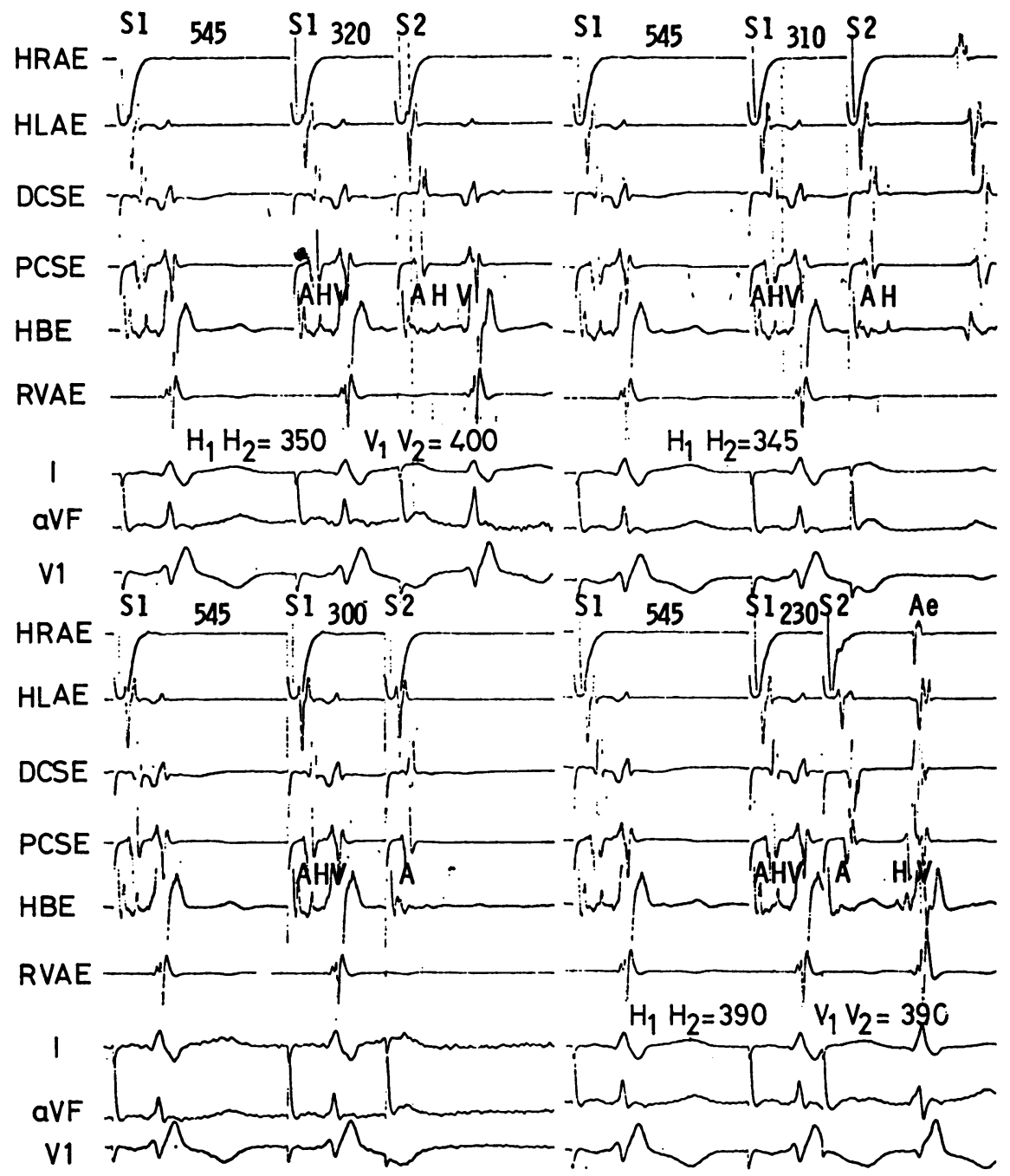

Fig. 2 Programmed atrial premature stimuli at progressively shorter coupling intervals in case 2. $H R A E$, high right atrial electrogram; HLAE, high left atrial electrogram; DCSE, distal coronary sinus electrogram; PCSE, proximal coronary sinus electrogram; $H B E, H i s$ bundle electrogram; $R V A E$, right ventricular apex electrogram; $I, a V F, V 1$, standard surface leads.

et al., 1973; Nowak and Neuss, 1974) is feasible in patients, similar to the cases reported here, with a normal HV time.

In our patients the minimal prolongation of the AH time in response to incremental atrial pacing (Bisset et al., 1973; Neuss et al., 1975), premature atrial stimulation (Castellanos et al., 1971; Aranda et al., 1976), and intravenous verapamil (Both et al., 1975; Seipel et al., 1976) is typical of the short PR interval, narrow QRS complex syndrome and more consistent with an extranodal bypass tract than an intranodal fast pathway. In the cases reported here, anatomical dissociation of the fast pathway from the AV node is very likely because conduction anterogradely through the slow AH pathway results in atrial echo beats with earliest activation on the proximal coronary sinus electrode (Narula, 1974; Agha et al., 1976; Amat-y-Leon et al., 1976). A concealed direct VA connection is excluded because the atrial echo beat occurs before ventricular activation.

A gap in anterograde conduction is defined as a zone within the cardiac cycle where an atrial premature beat fails to be conducted to the ventricles 
Table 3 Anterograde conduction characteristics at various basic atrial pacing rates

\begin{tabular}{|c|c|c|c|c|c|c|c|}
\hline \multirow[t]{2}{*}{ Case } & \multirow{2}{*}{$\begin{array}{l}\text { Basic cycle } \\
\text { length } \\
(\mathrm{ms})\end{array}$} & \multicolumn{2}{|c|}{ Fast $A H(A N)^{*}$ pathway } & \multicolumn{2}{|c|}{ Slow $A H$ pathway } & \multirow{2}{*}{$\begin{array}{l}\text { Anterograde } \\
\text { gap } \\
\left(A_{1} A_{2}\right)\end{array}$} & \multirow{2}{*}{$\begin{array}{l}\text { Atrial echo } \\
\text { zone } \\
\left(A_{1} A_{2}\right)\end{array}$} \\
\hline & & $\begin{array}{l}E R P \\
\left(A_{1} A_{2}\right)\end{array}$ & $\begin{array}{l}F R P \\
\left(H_{1} H_{2}\right)\end{array}$ & $\begin{array}{l}E R P \\
\left(A_{1} A_{2}\right)\end{array}$ & $\begin{array}{l}F R P \\
\left(H_{1} H_{2}\right)\end{array}$ & & \\
\hline 1 & $\left\{\begin{array}{l}610 \\
430\end{array}\right.$ & $\begin{array}{l}290 \mathrm{~ms} \\
(? 260) \\
290 \mathrm{~ms}\end{array}$ & $\begin{array}{l}310 \mathrm{~ms} \\
(? 260) \\
310 \mathrm{~ms}\end{array}$ & $\begin{array}{l}240 \mathrm{~ms} \\
-\end{array}$ & $\begin{array}{l}400 \mathrm{~ms} \\
-\end{array}$ & $\begin{array}{l}265-290 \mathrm{~ms} \\
-\end{array}$ & $\begin{array}{l}245-260 \mathrm{~ms} \\
-\end{array}$ \\
\hline \multirow[t]{2}{*}{2} & $\mid \begin{array}{l}610 \\
545\end{array}$ & $\begin{array}{l}305 \mathrm{~ms} \\
(? 265) \\
305 \mathrm{~ms} \\
(? 265)\end{array}$ & $\begin{array}{l}345 \mathrm{~ms} \\
(? 265) \\
345 \mathrm{~ms} \\
(? 265)\end{array}$ & $\begin{array}{l}215 \mathrm{~ms} \\
220 \mathrm{~ms}\end{array}$ & $\begin{array}{l}380 \mathrm{~ms} \\
390 \mathrm{~ms}\end{array}$ & $\begin{array}{l}270-310 \mathrm{~ms} \\
270-310 \mathrm{~ms}\end{array}$ & $\begin{array}{l}220-260 \mathrm{~ms} \\
225-255 \mathrm{~ms}\end{array}$ \\
\hline & $\begin{array}{l}500 \\
430\end{array}$ & $\begin{array}{l}290 \mathrm{~ms} \\
(? 240) \\
290 \mathrm{~ms}\end{array}$ & $\begin{array}{l}335 \mathrm{~ms} \\
(? 240) \\
325 \mathrm{~ms}\end{array}$ & $220 \mathrm{~ms}$ & $420 \mathrm{~ms}$ & $245-285 \mathrm{~ms}$ & $\begin{array}{l}225-240 \mathrm{~ms} \\
-\end{array}$ \\
\hline \multirow[t]{2}{*}{3} & $\int 610$ & $\begin{array}{l}370 \mathrm{~ms} \\
(\text { ( } 325)\end{array}$ & $\begin{array}{l}380 \mathrm{~ms} \\
(? 325)\end{array}$ & $260 \mathrm{~ms}$ & $415 \mathrm{~ms}$ & $330-365 \mathrm{~ms}$ & $265-325 \mathrm{~ms}$ \\
\hline & 375 & $370 \mathrm{~ms}$ & $385 \mathrm{~ms}$ & - & - & - & - \\
\hline
\end{tabular}

*Fast AH pathway refractory periods are measured in the conventional manner from the anterograde conduction curves. AN pathway refractoriness (effective and functional) is assumed to be the $A_{1} A_{2}$ interval at which conduction resumes after the anterograde gap (see text).

bracketed by zones of intact conduction. The gap phenomenon was first described by Moe et al. (1965) in the canine heart and subsequently extended to the human heart by Durrer (1968) and Goldreyer and Bigger (1969). Durrer interpreted his findings in terms of longitudinal duality of AV nodal conduction. Early atrial premature beats, conducting rapidly down one of two AV nodal pathways, reached the distal conduction system when it was still refractory and failed to reach the ventricles. Still earlier atrial premature beats found the fast AV nodal pathway refractory and conducted slowly down the alternate pathway to reach distal tissue after it had recovered, and conduction to the ventricles, therefore, resumed. Subsequent investigations by Wit and his associates (1970a) showed that the conduction failure of early atrial systoles occurred if the functional refractory period of the AV node was less than the effective refractory period of the His-Purkinje system and that conduction resumed in response to very early atrial beats if sufficient proximal delay allowed the recovery of distal tissue. This explanation did not require the existence of proximal conduction system duality. Many examples of anterograde (Agha et al., 1973; Gallagher et al., 1973; Wu et al., 1974) and retrograde gap (Akhtar et al., 1974a, b) have now been described and classified in terms of sites of distal block and proximal delay (Damato et al., 1976) and Durrer's (1968) original hypothesis still awaits confirmation.

Electrophysiological evidence of AV nodal dual conduction pathways is provided by the construction of an anterograde conduction curve (Moe et al., 1956). The atrial extrastimulus technique is used to derive values of $\mathrm{H}_{1} \mathrm{H}_{2}$ for each $\mathrm{A}_{1} \mathrm{~A}_{2}$ interval. $A$ plot of $\mathrm{H}_{1} \mathrm{H}_{2}$ intervals against corresponding $\mathrm{A}_{1} \mathrm{~A}_{2}$ values usually produces a smooth uninterrupted
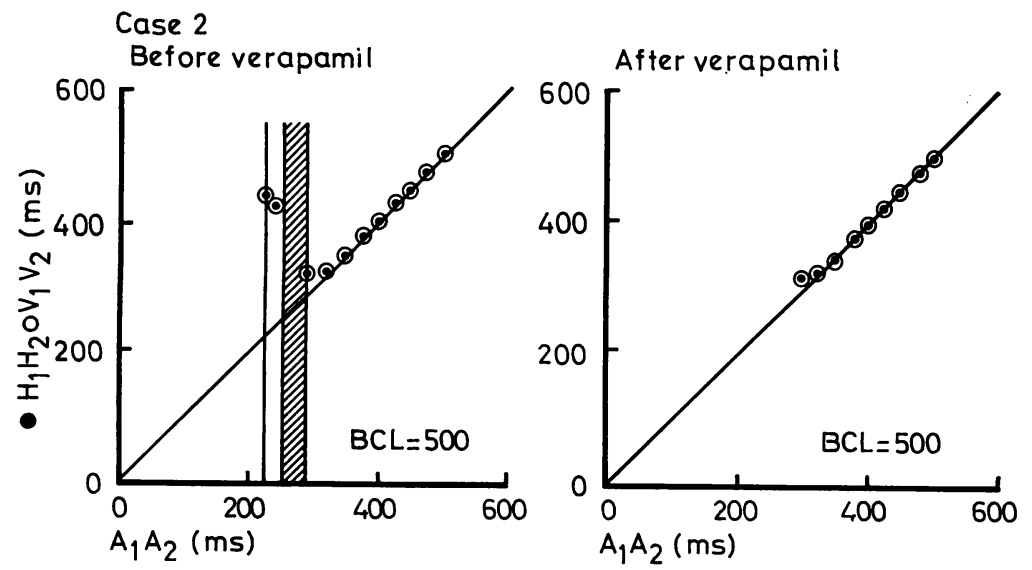

Fig. 3 Anterograde conduction curves before and after intravenous verapamil in case 2. 
curve (Wit et al., 1970b) but, where functional duality of AV nodal conduction is present, at critical $\mathbf{A}_{1} \mathbf{A}_{2}$ intervals, a sudden increase of $\mathrm{H}_{1} \mathrm{H}_{2}$ values may occur, when fast pathway conduction fails and slow pathway conduction is revealed (Denes et al., 1973). Such discontinuous anterograde conduction plots were evident in 3 of the 8 patients with the short PR interval, normal QRS complex syndrome studied recently in our laboratory and reported here. Others have found similar results in this syndrome (Denes et al., 1974b; Neuss et al., 1975; Aranda et al., 1976; Seipel et al., 1976). The discontinuity of the conduction curves in the present cases is emphasised by the gap in anterograde conduction which separates slow and fast pathway conduction (Fig. 2). Conduction failure above the level of the His bundle may mask intermediate $\mathrm{H}_{1} \mathrm{H}_{2}$ intervals, but the slopes of the apparently separate curves suggests that they are truly discontinuous.

Duality of conduction at AV nodal level is further supported by the occurrence of atrial echo beats, with low to high atrial activation, at $\mathrm{A}_{1} \mathrm{~A}_{2}$ intervals less than the effective refractory period of the fast pathway (Wu et al., 1975).

Complete or partial bypasses of the AV node short-circuit the normal physiological delay imposed by the AV node. Failure of AH prolongation should result in AH functional refractoriness being limited by the fast pathway's effective refractory period. Bisset et al. (1975) found statistically shorter AH refractory periods in patients with short $P R$ intervals. In our patients the functional refractory period of the fast pathway cannot be assessed from the shortest $\mathrm{H}_{1} \mathrm{H}_{2}$ interval achieved in response to atrial extrastimuli because it is uncertain where the fast pathway inserts into the AV nodalHis axis and because, during the gap in anterograde conduction, block occurs at a supra-Hisian level. Concealed fast pathway conduction probably continues during the anterograde gap zone because slow pathway conduction and atrial echo beats emerge simultaneously with the resumption in conduction. If the fast pathway's functional refractoriness is assumed to be the lower limit of the AH gap in conduction then conduction failure could be attributed, in part, to the short functional refractory period of the bypass. On the other hand, local geometric factors related to the abnormal insertion of the extranodal bypass into the normal AV nodel-His axis may be important (Janse, 1969).

Gap phenomena have been previously encountered in the short PR interval, normal QRS complex syndrome (Coumel et al., 1972; Aranda et al., 1976; Seipel et al., 1976). Aranda and his colleagues found anterograde gaps in 2 of 4 cases reported and resumption of anterograde conduction was not related to refractoriness of the fast pathway. Seipel et al. (1976) comment that anterograde gaps are frequently seen in this condition but do not mention the mechanism involved. In one illustration from their paper (Fig. 2, p. 154) conduction resumes with additional His-Purkinje delay, despite continued rapid $\mathrm{AH}$ conduction. In the three examples reported here the resumption of conduction is associated with an apparently sudden increase in the AH time and the simultaneous occurrence of atrial echo beats or sustained paroxysmal tachycardia.

Although conduction of premature atrial impulses at coupling intervals to the right of the anterograde gap (Fig. 1) appears to take place through a relatively fast pathway and conduction to the left of the gap through a dissociated slower pathway, the state and extent of $\mathrm{AV}$ conduction during the gap cannot be known with certainty because block occurs above the level of the His bundle. In case 2 at an $A_{1} A_{2}$ interval of $310 \mathrm{~ms}$ (Fig. 2) block occurs below the level of the His bundle in the presence of continued fast pathway conduction. At shorter $\mathrm{A}_{1} \mathrm{~A}_{2}$ intervals conduction block occurs proximal to the His bundle. It is probable that, throughout the gap, concealed fast pathway conduction continues to depolarise the lower $\mathrm{AV}$ junction at a coupling interval within the refractory period of the final common pathway to the ventricles. According to this hypothesis, slow pathway conduction is prevented by the concealed depolarisation of the lower $\mathrm{AV}$ junction and conduction resumes when $A_{2}$ finds the fast pathway refractory and is propagated with normal delay over the slow pathway. However, if the effective refractory period of the fast pathway is at the upper limit of the AV gap, block in this pathway may have revealed a gap in which both distal block and proximal delay were confined to the slow AH pathway. The upper limit of such a gap cannot be defined and this mechanism cannot fully account for the findings in case 2 and is unlikely in the other cases. In the examples reported here, the conduction of early atrial premature beats seems related to the shift of anterograde conduction to a slow intranodal pathway (Fig. 4) reminiscent of Durrer's (1968) original hypothesis.

Anterograde conduction characteristics assessed by the atrial extrastimulus method at higher atrial driving rates resulted in attenuation and abolition of the anterograde gap. The reduction in the gap zone resulted from improved final common pathway conduction as evidenced by the reduction of the upper limit of the gap. Abolition of the gap phenomenon resulted from failure of slow pathway conduction presumably because of increased AV nodal refractoriness at higher pacing rates (Denes et al., 1974a). 

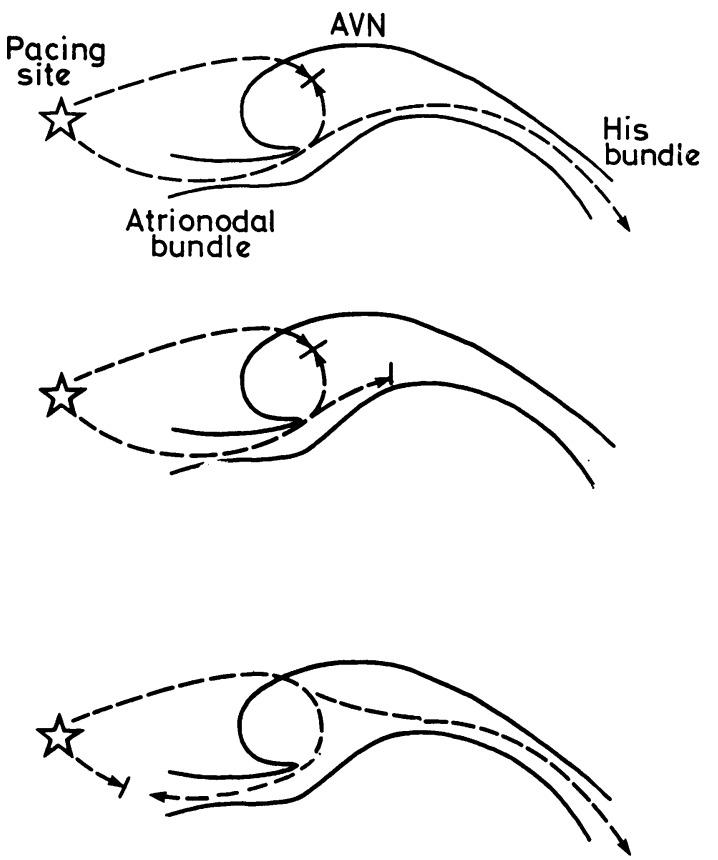

Fig. 4 Diagrammatic representation of the mechanism of gap production. Upper panel: conduction at intervals to the right of the gap; centre panel: block in $A V$. transmission producing a gap in the anterograde conduction curve; lower panel: resumption of conduction at intervals to the left of the gap.

Verapamil does not affect atrial or anomalous bypass tract conduction characteristics, but selectively lengthens both refractoriness and conduction time of the AV node (Spurrell et al., 1974; Zipes and Fischer, 1974). In all 3 patients verapamil prevented slow pathway conduction at $\mathrm{A}_{1} \mathrm{~A}_{2}$ values less than the refractory period of the fast pathway thus preventing the resumption of conduction at close atrial coupling intervals and abolishing the gap phenomenon.

Anterograde gap phenomena produced by block distal to the AV node are generally masked by fast basic pacing rates and by drugs such as betablockers (Wit et al., 1970a; Akhtar et al., 1974a) and verapamil which increase $A V$ nodal functional refractoriness. These manoeuvres cannot, therefore, be used to distinguish gap phenomena related to AV nodal duality from those produced by inhomogeneous refractoriness along the length of a single AV nodal-His Purkinje pathway.

It is seemingly paradoxical that improved conduction responsible for the short PR interval, normal QRS complex syndrome should lead to failure of conduction. Partial or complete AV nodal bypasses produce early and abnormal activation of distal junctional tissue and add another dimension to longitudinal inhomogeneity of atrioventricular transmission responsible for the high incidence of anterograde gaps in this syndrome.

\section{References}

Agha, A. S., Befeler, B., Castellanos, A. M., Sung, R. J., Castillo, C. S., Myerbury, R. J., and Castellanos, A. (1976). Bipolar catheter electrograms for study of retrograde atrial activation pattern in patients without pre-excitation syndromes. British Heart fournal, 38, 641-645.

Agha, A. S., Castellanos, A., Jr., Wells, D., Ross, M. D. Befeler, B., and Myerburg, R. J. (1973). Type I, type II and type III gaps in bundle-branch conduction. Circulation, 47, 325-330.

Akhtar, M., Damato, A. N., Batsford, W. P., Caracta, A. R., Vargas, G., and Lau, S. H. (1974a). Unmasking and conversion of gap phenomenon in the human heart. Circulation, 49, 624-630.

Akhtar, M., Damato, A. N., Caracta, A. R., Batsford, W. P. and Lau, S. H. (1974b). The gap phenomenon during retrograde conduction in man. Circulation, 49, 811-817.

Amat-y-Leon, F., Dhingra, R. C., Wu, D., Denes, P., Wyndham, C., and Rosen, K. M. (1976). Catheter mapping of retrograde atrial activation. Observations during ventricular pacing and AV nodal re-entrant paroxysmal tachycardia. British Heart fournal, 38, 355-362.

Aranda, J., Castellanos, J., Moleiro, F., and Befeler, B. (1976). Effects of the pacing site on A-H conduction and refractoriness in patients with short P-R intervals. Circulation, 53, 33-39.

Bisset, J. K., de Soyza, N., Kane, J. J., and Murphy, M. L. (1975). Altered refractory periods in patients with short P-R intervals and normal QRS complex. American fournal of Cardiology, 35, 487-491.

Bisset, J. K., Thompson, A. J., de Soyza, N., and Murphy, M. L. (1973). Atrioventricular conduction in patients with short PR intervals and normal QRS complexes. British Heart fournal, 35, 123-127.

Both, A., Seipel, L., and Loogen, F. (1975). Diagnostische Probleme beim LGL-Syndrom. In His-Bündel-Elektrographie, p. 147. Ed. by L. Seipel, F. Loogen, and A. Both. Schattauer Verlag, Stuttgart and New York.

Brechenmacher, C. (1976). Correlation between electrophysiology and anatomy in Wolff-Parkinson-White syndrome. In European Congress of Cardiology, Amsterdam, fune 1976.

Brechenmacher, C., Laham, J., Iris, L., Gerbaux, A., and Lenègre, J. (1974). Etude histologique des voies anormales de conduction dans un syndrome de Wolff-ParkinsonWhite et dans un syndrome de Lown-Ganong-Levine. Archives des Maladies du Coeur et des Vaisseaux, 67, 507-520.

Caracta, A. R., Damato, A. N., Gallagher, J. J., Josephson, M. E., Varghese, P. J., Lau, S. H., and Westura, E. E. (1973). Electrophysiologic studies in the syndrome of short P-R interval, normal QRS complex. American fournal of Cardiology, 31, 245-253.

Castellanos, A., Jr., Castillo, C. A., Agha, A. S., and Tessler, M. (1971). His bundle electrograms in patients with short $\mathbf{P}-\mathbf{R}$ intervals, narrow $Q R S$ complexes, and paroxysmal tachycardias. Circulation, 43, 667-678.

Clerc, A., Lévy, R., and Cristeco, C. (1938). A propos du raccourcissement permanent de l'espace P-R de l'ectrocardiogramme sans déformation du complex ventriculaire. Archives des Maladies de Coeur et des Vaisseaux, 31, 569-582.

Coumel, P., Wayneberger, M., Fabiato, A., Slama, R., Aigueperse, J., and Bouvrain, Y. (1972). Wolff-ParkinsonWhite syndrome. Problems in the evaluation of multiple 
accessory pathways and surgical therapy. Circulation, 45, 1216-1230.

Damato, A. N., Akhtar, M., Ruskin, J., Caracta, A., and Lau, S. H. (1976). Gap phenomena: antegrade and retrograde. In The Conduction System of the Heart: Structure, Function and Clinical Implications, p. 504. Ed. by H. J. J. Wellens, K. I. Lie, and M. J. Janse. Lea and Febiger, Philadelphia.

Denes, P., Wu, D., Dhingra, R. C., Chuquimia, R., and Rosen, K. M. (1973). Demonstration of dual A-V nodal pathways in patients with paroxysmal supraventricular tachycardia. Circulation, 48, 549-555.

Denes, P., Wu, D., Dhingra, R., Pietras, R. J., and Rosen, K. M. (1974a). The effects of cycle length on cardiac refractory periods in man. Circulation, 49, 32-41.

Denes, P., Wu, D., and Rosen, K. M. (1974b). Demonstration of dual A-V pathways in a patient with Lown-GanongLevine syndrome. Chest, 65, 343-346.

Durrer, D. (1968). Electrical aspects of human cardiac activity: clinical physiological approach to excitation and stimulation. Cardiovascular Research, 2, 1-18.

Durrer, D., Schuilenburg, R. M., and Wellens, H. J. J. (1970). Pre-excitation revisited. American fournal of Cardiology, 25, 690-697.

Gallagher, J. J., Damato, A. N., Caracta, A. R., Varghese, P. J., Josephson, M. E., and Lau, S. H. (1973). Gap in A-V conduction in man: types I and II. American Heart fournal, 85, 78-82.

Goldreyer, B. H., and Bigger, J. T., Jr. (1969). Spontaneous and induced reentrant tachycardia. Annals of Internal Medicine, 70, 87-98.

James, T. N. (1963). The connecting pathways between the sinus node and the AV node and between the right and left atrium in the human heart. American Heart fournal, 66, 498-508.

James, T. N., and Scherf, L. (1971). Specialised tissues and preferential conduction in the atria of the heart. American fournal of Cardiology, 28, 414-427.

Janse, M. J. (1969). Influence of the direction of the atrial wave front on $\mathrm{A}-\mathrm{V}$ nodal transmission in isolated hearts of rabbits. Circulation Research, 25, 439-449.

Lown, B., Ganong, W. F., and Levine, S. A. (1952). The syndrome of short P-R interval, normal $Q R S$ complex and paroxysmal rapid heart action. Circulation, 5, 693-706.

Mandel, W. J., Danzig, R., and Hayakawa, H. (1971). LownGanong-Levine syndrome. A study using His bundle electrograms. Circulation, 44, 696-708.

Moe, G. K., Mendez, C., and Han, J. (1965). Aberrant A-V impulse propagation in the dog heart: a study of functional bundle branch block. Circulation Research, 16, 261-286.

Moe, G. K., Preston, J. B., and Burlington, H. (1956). Physiologic evidence for a dual A-V transmission system.
Circulation Research, 4, 357-375.

Narula, O. S. (1974). Retrograde pre-excitation. Comparison of antegrade and retrograde conduction intervals in man. Circulation, 50, 1129-1143.

Neuss, H., Nowak, F. G., and Schlepper, M. (1975). Analyse der A-V-Ǔberleitung bei kurzer PQ-zeit. In His-BündelElektrographie, p. 153. Ed. by L. Seipel, F. Loogen, and A. Both. F. K. Schattauer Verlag, Stuttgart and New York. Nowak, F. G., and Neuss, H. (1974). Verhalten der AVUberleitung unter Frequenzbelastung bei Patienten mit kurzer PQ-zeit. Verhandlungen der Deutschen Gesellschaft für Kreislaufforschung, 40, 406-411.

Seipel, L., Breithardt, G., and Both, A. (1976). Atrioventricular (AV) and ventriculoatrial (VA) conduction pattern in patients with short P-R interval and normal QRS complex. In Cardiac Pacing. Diagnostic and Therapeutic Tools, p. 152. Ed. by B. Lüderitz. Springer-Verlag, Berlin.

Spurrell, R. A. J., Krikler, D. M., and Sowton, E. (1974) Concealed bypasses of the atrioventricular node in patients with paroxysmal supraventricular tachycardia revealed by intracardiac stimulation and Verapamil. American fournal of Cardiology, 33, 590-595.

Wit, A. L., Damato, A. N., Weiss, M. B., and Steiner, C. (1970a). Phenomenon of the gap in atrioventricular conduction in the human heart. Circulation Research, 27, 679-689.

Wit, A. L., Weiss, M. B., Berkowitz, W. D., Rosen, K. M., Steiner, C., and Damato, A. N. (1970b). Patterns of atrioventricular conduction in the human heart. Circulation Research, 27, 345-359.

Wolff, L., Parkinson, J., and White, P. D. (1930). Bundle branch block with short PR interval in healthy young people prone to paroxysmal tachycardia. American Heart Fournal, 5, 685-704.

Wu, D., Denes, P., Dhingra, R., and Rosen, K. M. (1974). Nature of the gap phenomenon in man. Circulation Research, 34, 682-692.

Wu, D., Denes, P., Dhingra, R., Wyndham, C., and Rosen, K. M. (1975). Determinants of fast- and slow-pathway conduction in patients with dual atrioventricular nodal pathways. Circulation Research, 36, 782-790.

Zipes, D. P., and Fischer, J. C. (1974). Effects of agents which inhibit the slow channel on sinus node automaticity and atrioventricular conduction in the dog. Circulation Research, 34, 184-192.

Requests for reprints to Dr A. J. Camm, Department of Cardiology, St Bartholomew's Hospital, West Smithfield, London EC1A 7BE. 